\title{
El impacto del vecindario en la movilidad económica: examinando las redes sociales de habitantes de tres barrios segregados de Salvador da Bahia (Brasil) a partir del concepto social isolation*
}

The impact of the neighborhood on the economic mobility, examining the social networks of inhabitants of three segregated neighborhoods from Salvador de Bahia (Brazil), from the social concept isolation.

\author{
O impacto do bairro na mobilidade econômica: examinando as redes sociais dos \\ moradores de três bairros segregados no Salvador da Bahia (Brasil), partindo do conceito \\ social isolation.
}

Stephan Treuke**

Forma de citar: Treuke, S. (2016). El impacto del vecindario en la movilidad económica: examinando las redes sociales de habitantes de tres barrios segregados de Salvador da Bahia (Brasil) a partir del concepto social isolation. Perspectivas, 1(1), 6-29.

Recibido:

Enero 12 de 2016

Aceptado:

Abril 20 de 2016

\section{Resumen}

Este artículo examina el impacto de neighborhood effects en la movilidad económica de los habitantes de tres barrios segregados de Salvador (Brasil). Según la hipótesis de social isolation, la inserción del individuo en un contexto socio-residencial marcado por altas tasas de pobreza y desempleo, junto a la insuficiente articulación con redes sociales e instituciones mainstream, obstaculizan su integración socioeconómica. Mientras tanto, la proximidad a un vecindario rico puede promocionar mayores estructuras de oportunidades. A partir de entrevistas investigando sobre la morfología de las redes egocentradas se corrobora que la contigüidad de la favela Nordeste de Amaralina a condominios de la clase média-alta beneficia la integración económica. Sin embargo, los mecanismos de segmentación social debilitan estos potenciales y las redes revelan un alto grado de homofilia y localismo. La segregación y la escasez de empleo en el barrio periférico Plataforma favorecen el encapsulamiento de las redes, mientras que el efecto socializador de instituciones públicas en el también periférico barrio Fazenda Grande II atenúa el impacto de la segregación. Las redes se constituyen mayoritariamente de bridging ties, promocionando la movilidad económica. El documento concluye subrayando la pertinencia del concepto social isolation en contextos de segregación donde existe una mayor congruencia entre espacio social y espacio geográfico en la

\footnotetext{
* Este artículo se basa en la presentación oral de la ponencia "El impacto del efecto-vecindario en procesos de movilidad económica de populaciones pobres inseridas en tres contextos de segregación en Salvador da Bahia (Brasil)" (XXX Congreso ALAS, San José - Costa Rica, 2015). Los resultados empíricos de este trabajo provienen de una investigación más amplia que indaga sobre las repercusiones de la segregación residencial en la movilidad económica de jóvenes expuestos a condiciones de vulnerabilidad social en Salvador da Bahia (Brasil) y cuenta con el apoyo financiero de la beca Coordenação de Aperfeiçoamento de Pessoal de Nível Superior (CAPES) para doctorandos.

** Doctorando en el Programa de Ciencias Sociales en la Universidad Federal de Bahia (Salvador da Bahia, Bahia - Brasil). Maestría en Filología Románica y en Geografía por la Universidad Justus-Liebig (Giessen, Hessen - Alemania). Dirección: Av. Tancredo Neves, 2227, Caminho das Árvores, CEP: 41.820-021, Condominio Home Prime I 2310, Salvador-Bahia (Brasil). Tel.: 005571991545812. StephanTreuke@hotmail.de
} 
constitución de las redes. Mientras que el Nordeste de Amaralina y Plataforma corren el riesgo de convertirse en barrios socialmente aislados, ya que desarticulados de los demás estratos sociales, las inversiones públicas en instituciones socialmente integrativas en Fazenda Grande II promueven las interacciones interclase.

Palabras clave: movilidad económica, neighborhood effects, Segregación residencial económica, social isolation, redes egocentradas.

\begin{abstract}
This article examines the impact of neighborhood effects on the economic ability of the inhabitants of three segregated neighborhoods in Salvador (Brazil). According to the social isolation hypothesis, the insertion of an individual in a socio-residential context marked by the high rates of poverty and unemployment, as well as the insufficient articulation with the social networks and the mainstream institutions, make difficult their socioeconomic integration.In the meantime, proximity to a wealthy neighborhood can promote greater opportunity structures. Based on interviews, investigating the morphology of egocentric networks, it is corroborated that the contiguity of the Northeastern Amaralina favela benefits the economic integration of middle-upper class condominiums. However, the mechanisms of social segmentation weaken these potentials and the networks reveal a high degree of homophile and localism. The segregation and the lack of employment in the peripheral neighborhood of Plataforma favor the encapsulation of networks, while the socializing effect of public institutions in the peripheral neighborhood of Fazenda Grande II attenuates the impact of segregation. Networks are mainly made up of bridging ties, promoting economic mobility.The paper concludes by highlighting the relevance of the social isolation concept in contexts of segregation where there is a greater congruence between social space and geographic space in the constitution of networks. While the Northeast of Amaralina and Plataforma run the risk of becoming socially isolated neighborhoods, since disarticulated from other social strata, public investments in socially integrative institutions in Fazenda Grande II promote interclass interactions.
\end{abstract}

Key-words: Economic mobility, neighborhood effects, Economic residential segregation, social isolation, egocentric networks.

\title{
Resumo
}

O presente artigo examina o impacto do neighborhood effects na mobilidade econômica dos moradores de três bairros segregados no Salvador (Brasil). De acordo com a hipótese social isolation, a inserção do indivíduo num contexto social residencial marcado pelas altas taxas de pobreza e desemprego, além da insuficiente coordenação com as redes sociais e instituições mainstream, dificultam sua integração sócio-económica. Por enquanto, a proximidade de um bairro rico pode promover estruturas de oportunidades maiores. Por meio de entrevistas pesquisando sobre a morfología das redes egocentradas confirma-se que a contiguidade da favela Nordeste de Amaralina com condomínios de classe méia-alta tras consigo benefícios de integração econômica. No entanto, os mecanismos de segmentação social enfraquecem estes potenciais e as redes revelam um elevado grau de homofilia e localismo. A segregação junto com a escassez de emprego no bairro periférico Plataforma propícia o encapsulamento das redes, enquanto o efeito socializador das instituições públicas no também bairro periférico Fazenda Grande II atenua o impacto da segregação. As redes constituense maiormente em bridging ties ,promovendo a mobilidade econômica. $\mathrm{O}$ documento conclui salientando a relevância do conceito social isolation nos contextos de segregação onde há uma maior coerência entre o espaço social e o espaço geográfico na constituição de redes. Enquanto o Nordeste Amaralina e Plataforma corren o risco de se tornar bairros socialmente isolados, já que 
desarticulados das outras camadas sociais, os investimentos públicos em instituições socialmente integradoras em Fazenda Grande II promovem as interações entre clases.

Palavras chave: segregação residencial econômico, neighborhood effects, social isolation, mobilidade econômica, redes egocentradas.

\section{Introducción}

Estudios sociológicos localizados en la intersección entre el análisis estructural del espacio y el examen de los patrones interaccionales de individuos y grupos sociales viviendo en las grandes ciudades, remontan a las reflexiones de Georg Simmel (1983[1902]), quién postula que las redes de sociabilidad en contextos urbanos estarían constituidas preponderantemente de lazos secundarios de composición heterogénea, baja intensidad y débil organización territorial (pp. 12-17). Mientras tanto, para Robert Park (1926), los lazos de vecindario frecuentemente abstraen de su carácter primario, íntimo y permanente en la urbe pero no pierden su pertinencia analítica ni su potencial de conflicto (pp. 8-11).

En las últimas décadas, estudios de la Sociología Urbana han integrado el análisis de los patrones de movilización de las redes sociales, en modelos explicativos sobre la reproducción de estructuras de pobreza urbana, atendiendo al hecho ampliamente documentado, que individuos inseridos en redes sociales más diversificadas y territorialmente dispersas, demuestran mayor suceso en la obtención de empleo (Granovetter, 1982; Tigges, Browne \& Green, 1998) y de apoyo social y emocional (Kaztman, 1999; Small \& Newman, 2001), mayor capacidad de mitigar o superar situaciones cotidianas de precariedad social (Wellman \& Wortley, 1990; Wilson 1987), mayor acceso a recursos (in)materiales (Briggs, 1998) así como a mejores condiciones de salud (Sharkey \& Sampson, 2010).
Desde la década de los 1980, un gran número de estudios académicos estadounidenses han dedicado su atención a explorar el modus operandi de los neighborhood effects ${ }^{1}$, concepto sociológico definido como las posibles ventajas y desventajas socioeconómicas afectando la vida de personas pobres en función de su inserción en determinados contextos socio-residenciales (Wilson, 1987, p. 144), para establecer asociaciones causales entre una determinada composición socioeconómica del vecindario y el desempeño y comportamiento del individuo, con respecto al acceso al mercado laboral, al rendimiento escolar, a la dependencia de programas sociales de transferencia de rentas, al hábito de consumo de drogas, al embarazo precoz y a la delincuencia, entre otros (Jencks \& Mayer, 1990, pp. 173-177; Small \& Newman, 2001, pp. 27-29).

Esta nueva vertiente de la Sociología Urbana Estadounidense, concibe el espacio como categoria analítica autónoma con capacidad de ejercer un impacto negativo, independientemente del desempeño socioeconómico del individuo y del contexto familiar. Rompiendo con la perspectiva atomista y culturalista que prevalecía en el debate sobre la pobreza urbana en los años 1980, Sampson, Raudenbusch y Earls (1997) postulan que las redes sociales pueden ser visualizadas como importantes transmisores de los neighborhood effects, argumentando

${ }^{1}$ El término neigborhood effects ha sido traduzido en español por efecto vecindario (Kaztman, 2001) y efeito-território (Andrade \& Silveira, 2013) o efeito do lugar (Ribeiro, 2008), entre muchos otros, en portugués. En virtud de la coexistencia de divergentes conceptos dentro del panorama de la Sociología Urbana latinoamericana, se mantiene en este documento la noción original de neighborhood effects, conceptualizada por Wilson (1987). 
que el contexto socio-residencial del barrio, constituye un incubador importante para la constitución de las redes sociales y la adquisición de capital social, al operar particularmente a través de los procesos de socialización primaria y secundaria (pp. 918919).

Focalizando los inner cities $^{2}$ racialmente segregados y habitados preponderantemente por afroamericanos y grupos de inmigrantes latinoamericanos empobrecidos, Tigges et al. (1998) revelan la preponderancia de redes interpersonales constituidas por bonding ties (Briggs, 2003, p. 2). Es decir, lazos primarios promocionando la cohesión social, la solidaridad intra-grupal y la estabilización socioeconómica del individuo en situaciones de emergencia. Mientras tanto, registran una proporción menor de bridging ties (Briggs, 2003, p. 10), en otras palabras, lazos sociales conectando el individuo a redes más amplias $\mathrm{y}$ diversificadas, susceptibles de vehicular informaciones y contactos valiosos para la movilidad económica y social.

Estas observaciones frecuentemente han precipitado la conclusión que la segregación residencial racial produce el encapsulamiento y la fragmentación de las redes interpersonales, en virtud del alto grado de localismo y homofilia $^{3}$ (McPherson, Smith-Lovin \& Cook, 2001, p. 429) de los lazos tejidos entre individuos y grupos sociales con escasos recursos económicos, dificultando la inserción del individuo en el mercado laboral formal (Granovetter, 1982; Massey \& Denton, 1993;

${ }^{2} \mathrm{La}$ inner city alude en este trabajo a barrios localizados en la región central de las metrópolis estadounidenses que comportan altas tasas de pobreza y desempleo, además de sofrer de la degradación física del habitat y de la ausencia de inversiones públicas en infraestructura y equipamientos urbanos.

${ }^{3}$ El término homophily, o homofilia en español, se refiere según McPherson et al. (2001), al hecho social de que se den con mayor probabilidad prácticas, hábitos, opiniones, conocimientos mutuos y relaciones comunes entre individuos con características sociales iguales que entre diferentes atributos. Por conseguinte, pares de individuos que convergen en sus atributos sociales, como edad, género, nivel educativo, clase o estatus social, son más susceptibles a tener mayor frecuencia en sus encuentros, más concordancia en sus opiniones o prácticas similares (p. 416).
Small, 2004; Wilson, 1987).

Sin embargo, existen evidencias empíricas que cuestionan las intercausalidades entre el contexto socio-residencial y la composición de las redes personales del individuo. Si bien que presuponen un impacto potencial del "factor socio-residencial" en la formación de las redes sociales del vecindario, Small (2004) rechaza la hipótesis de una incidencia generalizada de los neighborhood effects en la morfologia de las redes sociales de cualquier individuos (pp. 175-177). La importante distinción realizada por Sharkey (2006) entre imposed environments, engloba todos los factores potencialmente perjudiciales en el barrio donde el individuo vive, y selected environments, aludiendo a las personas y instituciones con los cuales el individuo en cuestión le interese por elección propia, enfatiza la idea que los individuos que comparten el mismo contexto socioresidencial pueden optar por completamente diferentes ambientes sociales y esferas de sociabilidad para la constitución de sus lazos personales (pp. 826-827).

Los orígenes de la discusión controversial remontan a la publicación del libro The truly disadvantaged: The Inner City, the Underclass, and Public Policy por Wilson (1987) que investiga sobre los mecanismos de reproducción de la pobreza extrema en el barrio fisicamente degradado South Side en la Chicago posfordista. El autor alude a la superposición de externalidades negativas ${ }^{4}$ perjudicando la integración en el mercado de trabajo formal de poblaciones mayoritariamente afroamericanas, viviendo en la inner city fuertemente segregada por

\footnotetext{
${ }^{4}$ El término "externalidades negativas" se refiere, en este contexto, a la exposición de habitantes de localidades marcadas por altas tasas de pobreza a una acumulación de riesgos (insalubridad y precariedad de la vivienda, degradación ambiental, violencia doméstica y en el espacio público, conducta violenta de la policía, entre otros) y factores negativos (aislamiento social/institucional/político, desempleo estructural, bajo desempeño escolar, delincuencia juvenil, discriminación estadística, entre otros) relacionadas al contexto socio-residencial, que favorecen la perpetuación de la situación precaria (Massey \& Denton, 1993; Wilson, 1987)
} 
criterios de raza y estatus económico (pp. 3-19).

Estas resultarían de la permanente exclusión del mercado laboral formal, de la fuerte concentración espacial de pobreza y del aislamiento vis-à-vis individuos e instituciones representando la sociedad mainstream americana. Conforme el concepto social isolation $^{5}$, la insuficiente articulación con redes sociales e instituciones de la sociedad mainstream y la ausencia de exposición a pares y modelos de rol que pudiesen transmitir referencias sociales normativas de la clase media, favorecería la reproducción de papeles sociales de la underclass ${ }^{6}$ (Wilson, 1987, pp. 56-62).

Dentro del panorama académico latinoamericano, estudios empíricos que analizan las consecuencias de la segregación "macro urbana", refiriéndose al patrón de aislamiento caracterizado por la distancia geográfica entre los barrios periféricos y las centralidades de la ciudad, en relación a la oferta de empleo y a los servicios urbanos, coinciden en indicar para el impacto cumulativo de externalidades negativas en la vida de sus habitantes, refiriéndose al acceso al mercado laboral, a las instituciones de educación pública y a los equipamientos y servicios urbanos, entre otros (Ribeiro \& Kaztman, 2008; Ribeiro \& Lago, 2001; Torres et al., 2008). Analizando las posibles repercusiones de la segregación residencial económica y de la segmentación social

${ }^{5}$ En analogía a la utilización original del concepto neighborhood effects en este trabajo, se optó también por la manutención del término inglés social isolation, dado el hecho que su traducción como "aislamiento social" no corresponde semanticamente a la definición conceptualizada por Wilson (1987) como "the lack of contact or of sustained interaction with individuals and institutions that represent mainstream society" (p. 60), es decir, la ausencia de contacto o de interacción con personas y instituciones representando la sociedad mayoritaria (traducción propia del autor).

${ }^{6}$ Dentro de la discusión controversial sobre las causas de la pobreza urbana, el término underclass engloba a poblaciones de la clase baja mayoritariamente de origen afroamericana, que se concentra en los ghettos centrales de las grandes ciudades estadounidenses. Debido a su contenido polémico, el término underclass fue posterioramente substituido por ghetto poor. en los patrones de sociabilidad, Marques (2007) revela el alto grado de homofilia y localismo inherentes a las redes personales de poblaciones habitando diferentes barrios pobres de São Paulo (pp. 156-159).

Mientras tanto, existe un mayor disenso en relación a las constelaciones urbanas socioespacialmente más heterogéneas, marcadas por la proximidad geográfica entre grupos socioeconómicamente distantes. Por un lado, Kaztman (2001) señala para las oportunidades de empleo promocionadas por la clase media y alta así como resalta los potenciales de la movilización de capital social a través de las instituciones públicas socializadoras como la escuela y a través de asociaciones filantrópico-asistencialistas (pp. 186-188). Por otro lado, Andrade y Silveira (2013) subrayan el alcance limitado de la articulación entre los grupos socialmente distantes ya que los lazos de empleo trascienden un carácter "subalterno" (empleada doméstica, portero, jardinero, técnico de servicios generales etc.) que reafirma la rigidez de la estratificación social (pp. 397-399).

Además, los mecanismos de segmentación social generarían un acceso a los equipamientos urbanos jerarquizado por clase social que impiden los intercambios de sociabilidad y refuerzan la estigmatización de las poblaciones frecuentemente consideradas como usurpadoras de los espacios dominados por la clase alta (Andrade \& Silveira, 2013; Ribeiro, 2008).

La primera sección, promueve una reflexión acerca de los conceptos sociológicos neighborhood effects y social isolation en la Sociología Urbana a partir de las contribuciones de Briggs (2003), Small y Newman (2001) y Wilson (1987) y señala para convergencias y divergencias empíricas dentro del espectro de estudios latinoamericanos sobre la segregación residencial económica. 
La segunda sección, introduce la metodología utilizada en el estudio cualitativo mientras que la tercera, examina las principales características de las redes egocentradas de los sesenta habitantes entrevistados. En la cuarta sección se discuten los principales resultados empíricos de la investigación mientras que las consideraciones finales promueven una contextualización crítica de la vertiente neighborhood effects en el panorama de los estudios urbanos latinoamericanos.

Atendiendo a la heterogeneidad de los resultados obtenidos en diferentes contextos de segregación residencial económica, este trabajo pretendió contribuir al debate sobre neighborhood effects en la Sociología Urbana Latinoamericana, a partir de un estudio de caso realizado en la tercera mayor ciudad de Brasil, Salvador da Bahia. Constituyendo como objetivo central investigar sobre el posible impacto de determinados externalidades negativas, resultantes de la exposición de los habitantes de tres barrios segregados a altas tasas de pobreza y desempleo, en los patrones de movilización de sus redes sociales para la integración económica. A partir de la comparación entre, por un lado, la invasión ${ }^{7}$ centralizada del Nordeste de Amaralina, cercada por condominios de la clase media y alta y, por otro lado, los barrios periféricos Plataforma y Fazenda Grande II, se indagó particularmente si existe una mayor interacción interclase y mejores estructuras de oportunidad de empleo en constelaciones de contigüidad geográfica entre clases socialmente distantes, en relación a contextos urbanos más periféricos.

\subsection{Reflexiones acerca del concepto neighborhood effects en la Sociología Urbana}

Estudios sociológicos contemporáneas, que intentan establecer asociaciones causales entre determinadas estructuras

"El término "invasión" señala para áreas habitacionales precarias de ocupación ilegal en Salvador da Bahia. sociales del vecindario y la asimilación y reproducción de específicos papeles sociales del individuo, frecuentemente recuperan la clásica cuestión de la Escuela de Chicago de cómo la composición social del vecindario, por ejemplo con respecto a su capacidad de control social, de eficacia colectiva y de transmisión intergeneracional de normas y valores sociales, influencia el desempeño y el comportamiento del individuo (Sampson, 1997) y cuál sería el impacto de la segregación residencial socioeconómica y de la pobreza en las tasas de criminalidad y en la movilidad social (Wilson, 1987).

Según Park, Burgess y McKenzie (1925), el fenómeno de la agregación espacial voluntaria de determinados grupos sociales relativamente homogéneos en las regiones centrales de las grandes ciudades estadounidenses, a partir de criterios étnico-raciales y socioculturales, era visualizado como transitorio puesto que constituía apenas la primera fase dentro de un ciclo migratorio ascendente de movilidad social de los diferentes grupos de inmigrantes involucrados en procesos de competición por el recurso escaso de vivienda (pp. 50-53). Abogando por una comprensión telelógica sobre los procesos migratorios intraurbanas de grupos sociales, que presuponía una organización radial-concéntrica del espacio urbano; los autores condicionaban la ascensión socioeconómica del individuo a su capacidad de asimilación social (adquisición de la ciudadanía estadounidense, asimilación lingüística y exogamia).

Mientras que la movilidad social ascendente se traducía espacialmente en una dispersión hacia los suburbios, redundando en la formación de barrios socioeconómicamente heterogéneos de la clase media estadounidense de origen europeo, la permanencia en el estado de concentración espacial de determinados grupos étnicos y raciales en los ghettos y enclaves étnicos socialmente más homogéneos, era considerada sinónimo de 
Vol. 1

No. 1

Jul - Dic 2016

ISSN: 2590-9215 (En línea) PP: 6-29 una baja capacidad de articulación intergrupal y interétnica que crearía obstáculos a la movilidad social y favorecería el desarrollo de comportamientos delincuentes (Park et al., 1925).

Distanciándose de este abordaje holísticoecológico, que partía de la primacía ontológica del vecindario sobre el desempeño y comportamiento del individuo, los estudios etnográficos de los antropólogos Hannerz (1967) y Wellman (1979) desafiaban a las premisas de la teoría de social disorganization ${ }^{8}$ postulada por Shaw y McKay (1942). Hannerz (1969) y Gans (1962), contraponiendo una visión de la ciudad constituida por un mosaico de "mundos sociales", cuya organización comunitaria se estructura a partir de criterios de etnicidad y clase de ocupación, y donde los patrones de interacción se fundamentan esencialmente en lazos primarios formando redes densas que proporcionan apoyo social y solidaridad intragrupal.

Posteriormente, el debate sobre la segregación residencial-racial en las grandes metrópolis estadounidenses, se polarizó entre una posición neoconservadora que culpabilizaba la misma underclass afroamericana concentrada en los conjuntos de habitación social de los inner cities, por la perpetuación de su condición de pobreza y exclusión socioeconómica (Murray, 2015) y una posición estructuralista que planteaba la deterioración de su situación socioeconómica con la reestructuración del mercado de trabajo (Wilson, 1987) respectivamente con las prácticas racialmente discriminatorias inherentes al mercado inmobiliario y a las políticas habitacionales del gobierno (Massey \& Denton, 1993).

${ }^{8}$ La hipótesis de social disorganization, o desorganización social, parte del presupuesto de que los habitantes de un determinado barrio comportando altas tasas de pobreza, heterogeneidad étnica y inestabilidad residencial enfrentan dificultades de resistir contra la presión social y la influencia destructiva de su contexto socioeconómico, lo que potenciaría el efecto de empobrecimiento, aumentaría la delincuencia y la dependencia de programas de transferencia de renta.
Wilson (1987) argumenta que, antes de la implementación de los Fair Housing Acts en 1968 y del declive de la industria fordista tradicionalmente localizada en las regiones centrales de las ciudades, la proximidad geográfica entre la clase de trabajadores y la clase media afroamericana en las inner cities todavía aseguraba la interacción entre los dos grupos económicamente distantes más verticalmente integrados a través de las instancias públicas de socialización como escuelas, iglesias, centros comunitarios y asociaciones filantrópicas (p. 144).

Atenuando situaciones de pobreza y de desempleo estructural, estas promocionaban el soporte (in)material y transmitían modelos de rol exitosos de la clase media. Las trasformaciones paradigmáticas de la estructura productiva rumo al posfordismo así como la implementación de leyes antidiscriminatorias democratizando el acceso a la vivienda propia en los suburbios tendrían ocasionado el "éxodo" de los afroamericanos con mayor poder adquisitivo y cualificación profesional. Como consecuencia, esta dinámica de movilidad residencial tendría elevado a niveles críticos la proporción de poblaciones pobres y desempleadas en estos barrios y contribuido a su aislamiento visà-vis la clase media afroamericana (Wilson, 1987, p. 20-32).

Inspirándose en la teoría de Wilson (1987), ganaron relevancia estudios sobre los neighborhood effects. Small y Newman (2001) sintetizan las principales vertientes temáticas de los estudios realizados en diferentes ciudades estadounidenses dentro del período de 1987 a 2000, elaborando una tipología que distingue entre dos categorías de análisis: los mecanismos de socialización y los mecanismos instrumentales.

El primero grupo examina grosso modo los mecanismos impactando en el transcurrir de los procesos de socialización primaria y secundaria de niños y adolescentes a través 
de la internalización de referencias, valores y comportamientos no exitosos de los pares (epidemic model) y de su naturalización $\mathrm{y}$ reproducción conforme determinados modelos de rol (collective socialization), a través del abordaje institucional imparcial por las autoridades públicas como la policía y los profesores de escuela (institutional model), a través de los obstáculos enfrentados en el proceso de asimilación lingüística (linguistic isolation model) y de la creación de una cultura antagónica a los modelos culturales mainstream de la clase media (oppositional culture) y, finalmente, a través de la privación relativa de los recursos materiales (relative deprivation).

El segundo grupo focaliza el grado de inserción de los individuos ya adultos en el mercado laboral y señala para las externalidades negativas de la agencia vis-à-vis determinadas configuraciones socioeconómicas del vecindario, levando en consideración la composición de las redes sociales del individuo y los patrones de articulación con individuos e instituciones representando la sociedad mainstream (network isolation model), el grado de acceso a recursos y instituciones públicas de buena calidad (resource model) y la capacidad de formar alianzas políticas para reivindicar intervenciones públicas y mejoras en el barrio (limitation of political alliances).

Dentro del espacio limitado de este trabajo, se atiende principalmente a los presupuestos teóricos del network isolation model, piedra angular de la hipótesis de social isolation formulado por Wilson (1987), para examinar el posible impacto de los neighborhood effects en la movilidad económica del individuo, a partir del análisis de sus redes egocentradas. Este autor argumenta que la segregación residencial socioeconómica y la extrema concentración de pobreza, repercuten en la extensión y diversidad de los lazos sociales del individuo a medida que la composición social homogénea en concomitancia con altas tasas de pobreza y desempleo, representan significativos obstáculos a la movilización del capital social para acceso a oportunidades de empleo en el mercado laboral formal.

Conforme la dicha hipótesis, la ausencia de interacción con individuos y grupos representando la sociedad mainstream americana confiere a la morfologia de las redes sociales un mayor grado de localismo y homofilia (McPherson et al., 2001, p. 429) en virtud de la predominancia de patrones isotópicos y modelos de referencia basados en valores, expectativas y comportamientos considerados como perjudiciales a la movilidad social y económica. El network isolation model, se fundamenta en las premisas de la Sociología Económica que considera como crucial la operacionalización del capital social a través de las relaciones interpersonales para integrar los individuos en redes más heterofilias con supuesta capacidad de promocionar activos para la movilidad económica y de fortalecer el soporte (in) material (Bourdieu, 1986; Coleman, 1988; Putnam, 2000).

En este sentido, Wilson (1987) recurre a la clásica distinción tipológica elaborada por Granovetter (1982) entre weak ties, es decir, redes de sociabilidad diversificadas formadas a base de contactos menos íntimos $\mathrm{y}$ menos frecuentes que proporcionan acceso a fuentes de informaciones no-redundantes sobre oportunidades de empleo, y strong ties, aludiendo a redes densas fundamentadas en contactos más íntimos y frecuentes constituidas en las esferas de sociabilidad de la familia, del vecindario y de los amigos; por las cuales circulan informaciones altamente redundantes. Complementando las reflexiones de Granovetter, Burt (1992) considera la cohesión intragrupal establecida a partir de strong ties con alto grado de homofilia y equivalencia estructural como un obstáculo para la ascensión social del individuo ya que 
dificultan la exploración de las structural holes $^{9}$ (pp. 65-75).

Briggs (2003) distingue entre dos dimensiones no mutuamente excluyentes de capital social estructurando las redes sociales de los actores sociales: De un lado, un tejido social denso organizado a partir de lazos entre iguales proporcionando la cohesión social, el fortalecimiento identitario, la solidaridad intragrupal y la estabilización de la situación cotidiana (get by), a través de redes altamente redundantes (bonding ties) y; de otro lado, lazos susceptibles de establecer "puentes" entre individuos y grupos sociales que proporcionan activos para la movilidad económica y social (get ahead). Estes lazos comportan un mayor grado de heterofilia y operan una inclusión en redes sociales más diversificadas y territorialmente dispersas (bridging ties) (pp. 3-10).

Unagranvariedaddeinvestigacionesempíricas pos-The truly disadvantaged, comprueban el carácter insular y local de las redes sociales de habitantes de barrios fuertementes segregados por criterios raciales o status económico y con tasas de pobreza superior al $40 \%$ de la población. Estas redes personales estarían constituidas preponderantemente por bonding ties proporcionando soporte (in)material en situaciones de crisis, mientras que los lazos extrapolando el contexto geográfico local y la misma clase social, están sobrepresentados (Briggs, 2003, p. 10). Tigges, et al. (1998) destacan que el tamaño reducido de las redes sociales y la menor proporción de contactos con personas con empleo formal estable o con nivel de educación superior, correlatan con una menor renta per cápita (pp. 72-74).

Noobstante, trabajosmás recientesexaminaron críticamente los presupuestos del network isolation model, señalando la dificultad

${ }^{9}$ El término structural holes se refiere a los contactos explorados por el individuo con capacidad de intermediar el acceso a recursos, status, prestigio y poder en función de la diversidad de informaciones o conocimientos que estas posiciones promueven (Burt, 1992, pp. 65-75). de hipotetizar un impacto generalizado de factores contextuales en las redes personales del individuo y exigiendo una mayor cautela en el examen de los patrones de sociabilidad para no asociar automáticamente los bridging ties con una mayor renta y los bonding ties como simples obstáculos a la ascensión económica. Los hallazgos de Venkatesh (2000) y Small (2004) comprueban que los bonding ties formados dentro del vecindario funcionan como importantes instancias de intermediación para la búsqueda de empleo en el mercado informal; estos canales dependen de la mutua confianza, reciprocidad y proximidad geográfica entre los actores sociales.

Otra deficiencia metodológica de las investigaciones sobre los neighborhood effects, consiste en el "sesgo de selección", abordado ya por Jencks y Mayer (1990), es decir, en la separación entre, por un lado el conjunto de factores intervinientes que pueden ser imputados a las idiosincrasias socioeconómicas del vecindario como categoría analítica sui generis, y por otro lado, las estructuras familiares y la propia trayectoria de movilidad residencial del individuo entrevistado. De igual manera, los estudios de Wellman (1979) ya evidencian que el barrio como unidad geográfica frecuentemente no congrua con el espacio social. La concepción parroquial de urban villages, (Gans, 1962, pp. 19-32) en el cual prevalecen los lazos primarios y coesos, parte de la existencia de unidades ecológicas autónomas, una realidad social que no corresponde a la organización de los patrones de sociabilidad contemporáneos caracterizados por interacciones que en muchos casos extrapolan el contexto geográfico local.

Mientras que en los Estados Unidos la reestructuración del mercado de trabajo y la vigencia de determinadas políticas federales de habitación social, continúan acentuando la concentración de las poblaciones 
afroamericanas y latinoamericanas pobres en los inner cities, en la Latinoamérica se observa también una fuerte (co) responsabilidad de las políticas urbanas en el proceso de consolidación de patrones de segregación residencial y segmentación social, que perjudican la integración económica de un significante contingente de poblaciones pobres (Sabatini, 2003, p. 19). En las ciudades latinoamericanas, el acceso al mercado de trabajo, a la vivienda, a la infraestructura y a los servicios urbanos constituyen los factores principales que determinan la distribución espacial de los grupos sociales en la ciudad.

En oposición a la dominación de patrones de segregación a partir de criterios raciales y étnicos en los Estados Unidos (Massey \& Denton, 1993), Sabatini, Cáceres y Cerda (2001) indican la prevalencia del patrón de segregación, a partir de criterios socioeconómicos en las ciudades latinoamericanas. En el transcurrir del acelerado proceso de urbanización, iniciado en la segunda mitad del siglo XX, se cristalizó un modelo de expansión de la ciudad "dualista", con expresivas disparidades entre, por un lado, un núcleo, o con de expansión, contemplado por las políticas urbanas y habitado por las clases media y alta con acceso al mercado inmobiliario formal y, por otro lado, una periferia desprovista de infraestructura y equipamientos urbanos que abriga a las poblaciones de baja renta, procedentes de las migraciones campo-ciudad en búsqueda de empleo en la industria.

Una gran variedad de trabajos académicos, evidencian fuertes correlaciones causales entre las idiosincrasias socioeconómicas de determinados comunidades periféricas y el comportamiento de riesgo de niños y adolescentes que (retro) alimentan la reproducción intergeneracional de pobreza y agudizan las desigualdades sociales en las metropólis latinoamericanas (Kaztman, 1999; Sabatini et al., 2003). Entre diferentes aspectos relevantes, los autores resaltan el impacto negativo del "factor residencial" en el rendimiento escolar y en la incidencia de la desafiliación institucional que afecta a los jóvenes que no desempeñan actividades profesionales ni estudian y ni buscan empleo en el mercado laboral formal (Kaztman, 2001, pp. 176-177).

En Brasil, estudios que focalizan contextos de macro-segregación en las metrópolis, confirman el impacto de externalidades negativas en la movilidad social de los habitantes de regiones periféricas. Ribeiro y Lago (2001), comparando el grado de inserción de habitantes de favelas y no-favelas en el mercado de trabajo formal en Rio de Janeiro, llaman la atención por la significante desventaja en termos de renta afectando el primero grupo. Los autores demuestran que los trabajadores habitando las favelas poseen una renta significantemente menor en virtud de los mecanismos que transforman el estigma territorial en prácticas discriminatorias en el mercado de trabajo.

Otro grupo de trabajo aborda el posible impacto de los mecanismos de segregación residencial tomando como proxy los niveles de escolaridad y la cualidad de las instituciones públicas de educación (Ribeiro \& Kolinski, 2009). Evidenciando un rendimiento escolar más bajo de los estudiantes habitando los municipios periféricos de las regiones metropolitanas, Torres et al. (2008) afirman que estas desventajas resultan de las insuficientes inversiones en guarderías infantiles y escuelas en estas áreas.

Las investigaciones realizadas por Marques (2007), en diversos barrios segregados de la Región Metropolitana de São Paulo, señalan para significantes convergencias con los argumentos de Wilson (1987) y Briggs (2003), a medida que confirman el generalizado alto grado de localismo y redundancia estructural que sobrepasan las redes personales de sus
No. 1

Jul - Dic 2016

ISSN: 2590-9215

(En línea)

PP: 6-29 
habitantes. El autor subraya que estas redes primarias impactan negativamente en la renta del individuo mientras que un patrón de sociabilidad más diversificado con mayor proporción de lazos formados en el ambiente de organizaciones de carácter asociativo, cultural y religioso incrementa la probabilidad de integración en el mercado laboral formal (Marques, 2007, pp. 156-162).

Aunque corrobore que inexisten lazos entre individuos transcendiendo la misma clase de renta, el autor no adhiere a la hipótesis de social isolation de la clase baja postulada por Wilson (1987), sino atribuye a las redes personales la capacidad de intermediación a recursos y servicios que permiten la obtención de auxilios sociales y facilitan la integración en el mercado laboral formal. El autor concluye afirmando que la segregación residencial económica no incide negativamente en el tamaño, en la cohesión y en la estructura de las redes (Marques 2007, pp. 110-111).

En constelaciones de proximidad geográfica entre grupos socioeconómicamente distantes, Kaztman y Retamoso (2005) afirman por el caso de Montevidéu que las relaciones sociales todavía están marcadas por el auxilio mutuo interclase que opera a través de instancias de socialización como la escuela, las asociaciones comunitarias y los espacios públicos de recreo. Según Andrade y Silveira (2013), la proximidad a los condominios cerrados del barrio Serra (Belo Horizonte), proporciona una amplia gama de ofertas de empleo a los habitantes de la favela Aglomerado da Serra, en comparación con los barrios periféricos inseridos en contextos de vecindario homogéneamente pobres (pp. 392-398). No obstante, los autores relevan la persistencia de las distancias sociales en las demás esferas de sociabilidad en virtud del acceso jerarquizado por clase social al transporte público, al sistema educativo, a los espacios públicos de recreo y a los recursos políticos.
Para Almeida y d'Andrea (2004), la población del barrio rico de Morumbi (São Paulo), además de promocionar oportunidades de empleo, contribuye financieramente al combate contra la pobreza y violencia en la favela vecina Paraisópolis a través de las redes filantrópico-asistencialistas y del apoyo a instituciones del Tercer Sector (guardería infantil, escuelas técnicas, puestos de salud y proyectos socioculturales) (pp. 105-106). La dialéctica entre integración de empleo y evitación social, también permea las relaciones entre poblaciones socioeconómicamente distantes más geográficamente aproximadas, según los hallazgos de Ribeiro (2008).

Estas revelan las tensiones sociales originadas por la dominación simbólica de los habitantes de Leblon, como recurso para "proteger seus capitais reificados no território de possíveis ameaças de desvalorização decorrentes da proximidade espacial com outros grupos" (Ribeiro, 2008, p. 18), vis$\grave{a}$-vis los vecinos del conjunto habitacional socialmente estigmatizado de Cruzada de São Sebastião. Abogando por una lectura bourdieusiana de los effets de lieu (Bourdieu, 1999), el autor enfatiza que los efectos de la naturalización del espacio, comprendido como las relaciones sociales redificadas, generan sistemas de referencias mentales que jerarquizan socialmente los espacios físicos, contribuyendo a la interiorización de determinados valores.

\section{Consideraciones metodológicas y muestra de datos}

En el marco de la investigación cualitativa fueron llevadas a cabo, en el período de mayo a noviembre de 2015 , entrevistas semiestructuradas de aproximadamente media hora de duración con veinte personas por cada barrio en diferentes locales y horarios (durante la semana y en los fines de semana). Las personas fueron abordadas aleatoriamente en la calle $y$, en algunos casos, fueron escogidas por la intermediación de los líderes de la 
comunidad y personas clave del barrio ya conocidos. Servían como local de estudio seis diferentes localidades comparables en tamaño y indicadores socio-demográficos, es decir, dos por cada barrio (Nordeste de Amaralina: Santa Cruz, Nordeste; Plataforma: Conjunto Habitacional Nova Primavera, Baixa do Caranguejo; Fazenda Grande II: Conjunto Habitacional Fazenda Grande II, Jaguaripe I). Las entrevistas fueron llevadas a cabo mayoritariamente en el ambiente domiciliar.

La amuestra se componía de $60 \%$ de mujeres y $40 \%$ de hombres, siendo que dentro de este grupo $40 \%$ pertenece a la franja etária de 15 25 años, $40 \%$ a la franja etaria de 26-45 años y $20 \%$ a la franja etaria de $46-65$ años. Dentro del grupo, el $40 \%$ de los individuos adultos se autocalifican como desempleados o sin renta estable, el 20\% afirman poseer renta per cápita igual o inferior a un salario mínimo (cerca de 200 dólares) y el 40\% de los entrevistados declaran recibir entre un a tres salarios mínimos. La proporción de entrevistados estudiantes, grupo no integrando en la categoría de la población económicamente activa, llega al 15\%.

Los tres barrios, el Nordeste de Amaralina, Plataforma y Fazenda Grande II, comportan todas altas tasas de pobreza y desempleo. $\mathrm{Su}$ población pertenece mayoritariamente a la clase socio-profesional popular (inferior) con bajo nivel de renta y grado de instrucción, conforme la clasificación ${ }^{10}$ de Carvalho y Pereira (2014). Es oportuno resaltar que en esta investigación, la elección de una matriz empírica geográficamente limitada, que define

\footnotetext{
${ }^{10}$ La tipología socio espacial construida por el Observatorio de Metrópoles a partir de datos censitarios de 2010 cruza las estructuras ocupacionales de la población económicamente activa de la Región Metropolitana de Salvador con otras variables (renta, escolaridad, situación ocupacional, sector de actividad económica y sector institucional). La distribución de las categorías socio-profesionales en el espacio usa las áreas definidas por una agregación de sectores censitarios (áreas de ponderação) utilizados en los censos del Instituto Brasileño de Geografía y Estadística (IBGE) y distingue entre los segmentos superior, édio-superior, medio, medio-popular, popular, popular-inferior e popular-agrícola (Carvalho \& Pereira, 2014).
}

los tres barrios como unidades ecológicas independientes, traduce la centralidad del contexto social local en la constitución y movilización de las redes sociales de los habitantes entrevistados.

En el $86 \%$ de los casos, las interacciones ocurren dentro de las fronteras territoriales del respectivo barrio, lo que señala para una significante congruencia entre el espacio residencial y el espacio social. Concomitantemente, el papel preponderante (en el 94\% de los casos) que asumen los lazos informales en la búsqueda de empleo justifica la exclusión de otras posibilidades formales de búsqueda de empleo como el reclutamiento a través de agencias de intermediación de empleo, los anuncios en el periódico/internet y los concursos públicos.

Durante las visitas al barrio, era aplicado, en primer lugar, un cuestionario indagando sobre las características generales de la persona entrevistada incluyendo datos biográficas, sobre la composición familiar y el hogar, la renta, el nivel de escolaridad, el status de empleo, la trayectoria en el mercado de trabajo y los años de permanencia residencial en el barrio. En segundo lugar, los individuos entrevistados fueron solicitados a pronunciar sobre la organización de sus redes egocentradas en termos de participación proporcional en las diferentes esferas de sociabilidad, cuáles sean: familia, vecindario, amistad, trabajo, estudios, vida asociativa (no) laical y diversión. Las esferas de sociabilidad representan estructuras sociales permanentes que se constituyeron a partir de procesos de especialización social, incluyendo círculos de interés y de convivencia, y ambientes institucionales, entre otros. Se trata de espacios sociales cognitivamente comprendidos que varían según la auto-clasificación de la persona entrevistada y que agregan un determinado número de contactos personales.

Mientras que una mayor inserción del individuo en las tres primeras esferas - familia, 
vecindario y amigos - transciende el énfasis de los lazos primarios en la constitución de sus redes personales, caracterizadas por un nivel más alto de homofilia y localismo (Briggs, 2003; Granovetter, 1982), se hipotetiza que la organización a partir de las esferas trabajo, estudios, vida asociativa (no) laical y diversión favorece la constituición de lazos más heterofílias y territorialmente dispersas.

Los entrevistados debían fornecer informaciones más detalladas sobre la movilización de las redes egocentradas tejidas en el ambiente de las supracitadas esferas de sociabilidad para la obtención de empleo o de informaciones sobre vacantes de empleo, así como para el acceso a recursos financieros y de apoyo social y emocional. La extracción de estas informaciones permitía la comparación entre la morfología de las redes egocentrados de los habitantes inseridos en los tres barrios a partir de los indicadores: proporción relativa de participación del individuo en determinada esfera de sociabilidad, grado de diversidad de sus redes personales (inserción en diferentes esferas de sociabilidad) y grado de localismo de sus redes.

Complementariamente, la observación participativa realizada en los tres barrios objetivaba conocer con mayor profundidad las situaciones diarias de interacción entre los habitantes y colectar importantes datos sobre el contexto socio-residencial en cuestión. Para ayudar en la obtención de confianza y familiaridad con las personas entrevistadas, se las acompañó en sus rutinas y actividades diarias y se visitaran, junto a ellas, diferentes asociaciones comunitarias, iglesias, escuelas y lugares de encuentro público, que en su mayoría estaban localizados dentro del propio barrio. Además, se frecuentaban las reuniones del vecindario que se celebraban generalmente una vez por mes, para profundizar el conocimiento sobre la organización social y sobre los patrones de sociabilidad dentro del vecindario. Durante las visitas se anotaba los principales hallazgos en un diario de campo que proporcionaba valiosas informaciones sobre el local y contexto del estudio cualitativo, que no se obtuvieron a base de las entrevistas.

El análisis de las redes egocentradas atendió esencialmente por la percepción subjetiva de los individuos sobre sus redes sociales movilizadas en diversas situaciones de vida y, por ende, reflejó la representación cognitiva de las personas entrevistadas sobre sus contactos. En este sentido, el estudio de la morfología de las redes egocentradas partió de la auto clasificación de la persona entrevistada sobre sus patrones de sociabilidad, lo que incluyó también los lazos sociales activados en el ambiente de determinadas esferas de sociabilidad en las cuales el individuo no participa periódicamente mas a los cuales se afilia según su propia avaluación.

A pesar de no constituir una muestra estadísticamente significativa, las sesenta entrevistas fornecieron importantes informaciones sobre la organización de los patrones socio-interacciónales de las personas que, además de vivir en barrios segregados, se ven expuestas a altas tasas de desempleo y pobreza. La pertinencia de este estudio se justifica por su enfoque comparativo, que atiende para la variabilidad de los tres contextos de segregación analizados. El examen de la morfología de las redes egocentradas reveló diferentes estrategias de movilizar los lazos sociales para la integración económica y la obtención de recursos materiales, sociales y afectivos. Además, demostró como determinadas estructuras de redes sociales pueden atenuar o reproducir situaciones de pobreza en barrios segregados en Salvador da Bahia. 


\section{Análisis comparativo de la morfología de las redes egocentradas en los tres barrios}

\subsection{El barrio de Nordeste de Amaralina}

La localización del barrio Nordeste de Amaralina, apunta hacia el patrón de segregación residencial fractal, debido a su status de enclave pobre dentro de la región Orla Atlántica Norte, dominada por el segmento socio-profesional medio-superior (Carvalho \& Pereira, 2014). Su terreno accidentado formado por vales y colinas fue invadido por sucesivas olas de migración campo-ciudad desde la década de los 1960, provocando su rápido crecimiento demográfico (25.466 habitantes según IBGE 2000).

La situación de precariedad habitacional en conjunción con altas tasas de desempleo $(61 \%)$ se ve agravada por un generalizado clima de inseguridad, imputado a las disputas por el tráfico de drogas. Durante las visitas al barrio, se observó la expresiva fragmentación territorial en micro-áreas por fracciones rivales que controlaban el tráfico de drogas, lo que restringía los patrones de interacción social de las personas entrevistadas a las regiones más próximas a la vivienda. Según los entrevistados, esta inseguridad dificulta el dislocamiento dentro del propio barrio $\mathrm{y}$ interfiere en sus rutinas cotidianas, ya que la entrada de personas no-residentes en determinadas áreas es considerada como una amenaza.

La distribución de los lazos conforme esferas de sociabilidad revela la primacía de las instancias primarias como la familia $(30 \%)$, el vecindario $(15 \%)$ y los amigos $(10 \%)$ en la constitución de las relaciones sociales y en la movilización del capital social en procesos de integración económica. Mientras tanto, los lazos tejidos en el ambiente de las relaciones de trabajo (15\%), de los estudios (5\%) y de diversión $(5 \%)$, así como a través de la participación en redes asociativas laicales $(10 \%)$ y de la afiliación a la iglesia y otros grupos religiosos $(10 \%)$, revelan una menor presencia.

Estos lazos primarios, fundamentados en contactos frecuentes entre individuos congéneres, pueden ser visualizados como estructuras de apoyo a la supervivencia de corto plazo, movilizadas en diversas situaciones de emergencia y de estabilización económica (get by), como en el caso de insolvencia, desempleo o de dependencia de drogas. Además, los bonding ties (Briggs, 2003, p. 2) funcionan como principales canales de información sobre las oportunidades de empleo exigiendo baja calificación profesional que se concentran en su gran mayoría en el sector informal.

La proximidad geográfica a los barrios del segmento medio-superior es avalada por los entrevistados como elemento potenciador de las chances de ser empleado en comparación con las localidades más periféricas. En el conjunto de las veinte personas, cuatro desempeñan diferentes servicios remunerados en los condominios de los barrios vecinos. En este sentido, es oportuno subrayar la importancia de dos personas-clave trabajando como porteros en dos condominios de lujo que disponen de informaciones y contactos privilegiados sobre diferentes oportunidades de empleo que surgen espontáneamente conforme la demanda de los habitantes del vecindario rico, como el lavado de coches y los pequeños servicios de manutención del edificio. La exploración de estas bridging ties se traduce en mayores rendimientos para los dos entrevistados que accedan estas structural holes, en el sentido de Burt (1992), pese a que no se trata de una renta estáble.

Sin embargo, y abstrayéndose de la selectiva integración económica que ocurre mayoritariamente en formas de actividad profesional de baja calificación (portero, jardinero, empleada doméstica etc.), las distancias sociales se mantienen en todas 
las demás esferas de sociabilidad. A pesar de la fuerte relevancia de las numerosas organizaciones de carácter asociativo y cultural, como las asociaciones comunitarias, los grupos de capoeira y de baile, los clubes de fútbol, entre otros tantas, que concurren por la socialización y por la construcción identitaria de sus habitantes, es importante resaltar que éstas también privilegien el revigoramiento de la solidaridad intergrupal sin promocionar "puentes" para las redes externas al barrio. Las redes tejidas en este contexto de sociabilidad, revelan un carácter fragmentado e insular.

A través de estas redes, circulan informaciones altamente redundantes ya que reúnen en su gran mayoría personas similares en termos socioeconómicos. La proporción de redes de sociabilidad formadas en el ambiente de la iglesia y de otros grupos religiosos es relativamente baja en comparación con los otros dos barrios. Se trata preponderantemente de bonding ties coesas, tejidas entre miembros íntimos de la misma congregación, que fortalecen la solidaridad intragrupal y promocionan diversos recursos para la estabilización socioeconómica de los habitantes a través de las diferentes actividades sociales realizadas en el barrio, como consultas jurídicas gratis, distribución de alimentos, concesión de pequeños préstamos o promoción de apoyo emocional en caso de enfermedad o muerte de parientes, entre otros.

Abstrayéndose de esta función, para tres personas, la participación en asociaciones no-laicales favoreció la inserción económica en el mercado laboral informal, resaltando la importancia de personas-clave que disponen de contactos e informaciones privilegiados sobre oportunidades de empleo en el barrio.

Los mecanismos de la segmentación social y el acceso "dualizado" a la infraestructura, al transporte y a los servicios públicos producen cierto "confinamiento" en la vida de los habitantes entrevistados dentro de su barrio, hecho que repercute en un mayor grado de homofilia y de localismo de las redes, particularmente aquellas construidas en las esferas del vecindario y de la escuela. Las instituciones educativas públicas en el barrio, sufren de la falta de inversiones y fueron calificadas de forma unánime como lugares peligrosas en virtud de la presencia de fracciones rivales, diseminando modelos de comportamientos y prácticas perjudiciales para la ascensión social y económica. De los tres adolescentes entrevistados apenas uno clasificó la escuela como lugar central en la constitución de sus redes personales.

Además, la diferenciada apropiación conforme clases de los espacios públicos y de recreo, que pudiesen favorecer el contacto y el intercambio de sociabilidades entre los grupos socialmente distantes, shoppings, plazas y parques, reflecta los bajos niveles de renta que restringe la participación de la mayoría de los habitantes de Nordeste de Amaralina a las opciones locales del barrio. La concentración de equipamientos urbanos de alto patrón (hospitales, universidades privadas y supermercados sofisticados) a lo largo de la Avenida Juracy Magalhães, línea divisora entre la favela Nordeste de Amaralina y los condominios de la clase media-superior (Horto Florestal), no ofrece ninguna ventaja para la población pobre, exceptuándose el acceso privilegiado al transporte público. La mayor diversión accesible para los entrevistados proporciona la Praia de Amaralina, lugar evitado por la clase mediaalta en virtud de la alta frecuencia de robos y asaltos.

\subsection{El barrio de Plataforma}

La localización de Plataforma, barrio ubicado en la región pobre del Suburbio Ferroviário, señala para el paradigma de la segregación operando a escala macrourbana, caracterizado por la distancia geográfica a los puestos de 
trabajo y a los servicios urbanos concentrados en el centro de la ciudad y en la Orla Atlntica Norte. El barrio, limitado por un lado por la Baía de Todos os Santos y por otro lado por el Parque São Bartolomeu creció alrededor del núcleo de la antigua Vila Operária, cuya implementación fue motivada por la inauguración de la ferrovía Calçada-Paripe en 1860 y por la instalación de la Fábrica Têxtil São Braz en 1875, desactivada en 1959. La mayoría de los cerca de 58 mil habitantes sufre de la precariedad de las condiciones de habitación, salud y seguridad; situación ensombrecida por altas tasas de desempleo $(47,3 \%)$ y por el bajo rendimiento media de la población.

Analizando la variabilidad de los patrones de sociabilidad de los veinte habitantes entrevistados, llama la atención el alto grado de homofilia, localismo y redundancia que sobrepasa casi la totalidad de las redes egocentradas, mismo controlando por esferas de sociabilidad. La inserción de los individuos en diferentes contextos de sociabilidad subraya la centralidad de la familia (35\%) y de la Iglesia u otros grupos religiosos (20\%) en la estructuración de los lazos sociales y en la movilización de las redes para la obtención de un empleo o de recursos (in)materiales, seguidas por las esferas vecindario $(10 \%)$, vida asociativa laical (10\%) amigos (10\%) trabajo (5\%), estudios (5\%) y diversión (5\%).

En contraste con la mayor dispersión espacial y diversidad de las redes sociales beneficiando la integración de algunos habitantes del Nordeste de Amaralina en actividades profesionales, el contexto social local prevalece en la formación de la mayoría de las redes analizadas en el caso de Plataforma, hecho que restringe expresivamente las interacciones de sus habitantes con individuos y grupos sociales no-locales. En convergencia con los resultados de Wilson (1987) y Tigges et al (1998), la mayoría de los entrevistados accedan menos bienes y servicios, tanto vía el mercado como por ayuda social, dado el alto grado de localismo y homofilia. La configuración de las redes sociales reduce la circulación de informaciones sobre oportunidades de empleo a las esparzas potencialidades endógenas del barrio. Un factor limitador representan los gastos necesarios para desplazarse diariamente para las regiones centrales de la ciudad, los cuales concentran los puestos de trabajo y servicios urbanos.

La movilización de las redes sociales para la obtención de un empleo, ocurre principalmente en el ambiente de las familias extensas que funcionan como importantes canales por los cuales circulan informaciones sobre opciones de trabajo informal en el barrio. La primacía de las relaciones domiciliares en el enfrentamiento de las diversas adversidades cotidianas y en la provisión de recursos (in)materiales, se explica por la confianza, reciprocidad y solidaridad que estas redes establecen entre sus miembros a partir de contactos frecuentes mientras que prima un alto grado de desconfianza en las relaciones interpersonales constituidas en las esferas del vecindario y de amistad. En este sentido, los informantes explican el encapsulamiento de las redes con la retracción del Estado en la provisión de bienestar y de seguridad en el barrio y con la precariedad del mercado de trabajo, exigiendo el auxilio mutuo entre los miembros de familia.

Concerniente a la formación de las redes sociales a partir de las esferas de sociabilidad vecindario y amistad, llama la atención la reticencia de los habitantes de integrar personas desconocidas en sus redes existentes. A partir de la observación participativa se observó un fuerte énfasis de la vida social de los entrevistados al espacio geográfico más próximo de la vivienda, particularmente en el caso del Conjunto Habitacional Nova Primavera. En contraste con los otros dos barrios, se observa para este
No. 1

Jul - Dic 2016 ISSN: 2590-9215 (En línea) PP: 6-29 
Vol. 1

No. 1

Jul - Dic 2016

ISSN: $2590-9215$ (En línea) PP: 6-29 caso un significante declive de la importancia del vecindario como contexto de constitución y manutención de los lazos, que restringe los intercambios de sociabilidad y el apoyo mutuo a un número muy reducido de vecinos. Este fenómeno contribuye a una creciente fragmentación territorial de las relaciones interpersonales que se organizan en pequeños núcleos a partir de criterios de proximidad, reciprocidad e confianza. En prácticamente todos los casos analizados, las redes tejidas en los ambientes del vecindario y amistad se fundamentan en strong ties (Granovetter, 1982).

O social isolation favorece la construcción de patrones de sociabilidad isotópicos, basados en experiencias y comportamientos locales, que toman como referencia individuos congéneres compartiendo la misma situación de precariedad. Se registra una baja dinámica de adhesión a organizaciones comunitarias de carácter asociativa y cultural, exceptuándose un grupo de capoeira y una asociación comunitaria. Ambos promueven soporte social de corto plazo y constituyen un importante espacio de sociabilidad. Fuera de la esfera de familia, el mayor apoyo social proviene de las asociaciones de carácter religioso que fortalecen la cohesión y solidaridad intragrupal mientras que mantienen una estructura truncada y hermética para nocongregados. Estas bonding ties, operan como circuitos de reciprocidad por los cuales circulan beneficios materiales, afectivos y cívicos, como ayuda en la construcción de la vivienda, pequeños préstamos, contactos de empleo, auxilio en situaciones de enfermedad $\mathrm{y}$ de dependencia física.

Las asociaciones no-laicales agregan la gran parte de las personas-clave que promueven el acceso a informaciones sobre estructuras de oportunidades, mayoritariamente ofrecidas en la misma localidad y en el sector informal. No obstante, la participación en las actividades sociales no garante automáticamente mayores rendimientos, siendo que en el $70 \%$ de los casos la afiliación a una iglesia o a otro grupo religioso no alteró significantemente la situación de precariedad.

Los habitantes del barrio convergen en indicar para la fragilidad de las oportunidades educativas y por la escasez de guarderías infantiles en la región. $\mathrm{La}$ exposición a congéneres y pares habitando el mismo barrio es avalada de forma unánime como desfavorable a la trayectoria socioeconómica por los tres alumnos adolescentes entrevistados que reclaman de la falta de perspectivas y de la baja calidad educativa. En varias ocasiones se generan confrontaciones armadas entre alumnos adolescentes en frente de la escuela local. La falta de oportunidades de empleo formal y la creciente ociosidad de los jóvenes son factores visualizados como estimulantes por el envolvimiento con el tráfico de drogas. El acceso a opciones de diversión, concentradas en las centralidades de Salvador, permanece fuera del alcance de los habitantes entrevistados, ya que las despensas para el desplazamiento y consumo extrapolan el presupuesto.

\subsection{EI barrio de Fazenda Grande II}

A pesar de su ubicación periférica, el barrio de Fazenda Grande II comporta el mayor grado de heterogeneidad dentro de los tres barrios, tanto con respecto al perfil socioeconómico de su población cuanto de su vecindario geográfico inmediato. Totalizando aproximadamente 35.000 habitantes, el barrio creció con la simultánea instalación de poblaciones pertenecientes al segmento popular en conjuntos monofuncionales construidos por el Banco Nacional de Habitação en los años 1970 y la ocupación espontánea de la clase popular-inferior de los espacios vacíos de alta declividad. En este sentido, se observan expresivas asimetrías socioeconómicas entre el grupo de entrevistados de la categoría popular-inferior que habitan Jaguaripe I, 
invasión comportando altas tasas de pobreza y desempleo, y los inquilinos de los conjuntos habitacionales del barrio Fazenda Grande II que se inserten en la categoría socioprofesional media-inferior (Carvalho \& Pereira, 2014).

La distribución de los lazos conforme esferas sociales subraya la centralidad del trabajo (30\%) y de los estudios (15\%) en la construcción de la sociabilidad de los individuos entrevistados así como resalta la importancia de las redes asociativas laicales $(15 \%)$ en la movilización de los contactos para la obtención de empleo y recursos (in) materiales, mientras que se registra una concentración menor en las esferas familia $(10 \%)$ vecindario $(10 \%)$, amigos $(10 \%)$, iglesia o demás grupos religiosos $(5 \%)$ y diversión $(5 \%)$.

Se observa una mayor conectividad de las personas con individuos o grupos externos al barrio que amplían el recurso a informaciones no-redundantes y movilizan el capital social para ganar acceso a mejores servicios sociales. Para este grupo disminuye la importancia de la familia extensa en la movilización de las redes para la integración en el mercado de trabajo. Existe una mayor diversidad y extensión de las redes egocentradas en comparación con los dos barrios previamente analizados. Sin embargo, la división entre los inquilinos del condominio y los habitantes de la invasión se reflecta en el grado de localismo y en los grados de movilización de recursos (in) materiales a base de los lazos de vecindario, ambos significantemente más altos en el caso de los habitantes de Jaguaripe I.

A la mayor proporción de contactos formados en el ambiente de las relaciones de trabajo formal corresponde un mayor grado de heterofilia de las redes, confirmándose la observación de Marques (2007) sobre la importancia de inserción en comunidades profesionales para la diversidad de la sociabilidad de las personas. Dentro del conjunto de las veinte personas, tres trabajan en el comercio local y cinco en los barrios circunferentes, todas en relaciones de empleo estable. Dentro del panorama de los tres barrios analizados en este trabajo, se observa que los lazos sociales tejidos en el ambiente de la iglesia o de otros grupos religiosos poseen menor relevancia mientras que se registra una fuerte tendencia de afiliación a organizaciones de carácter asociativa y cultural. De las veinte personas entrevistadas, siete afirman haber movilizado sus contactos a través de estas redes para acceder recursos (in)materiales así como para reivindicar mejoras infraestructurales en el barrio.

Es importante resaltar la centralidad de las diversas asociaciones de habitantes distribuidas por las dos áreas analizadas, en su función de crear un clima de solidaridad y de cohesión que reúne a la población en la lucha para la implementación de guardería infantiles y puestos de salud en el barrio, y en situaciones de riesgo como en caso de desmoronamiento de casas en las regiones de alta declividad de Jaguaripe I. Esta combinación de bonding y bridging ties posibilita, además de la indicación para diferentes empleos, la movilización política para obtener bienes comunes a través de redes más dispersas y diversificadas que amplían la oferta de informaciones sobre beneficios sociales, oportunidades de empleo, campañas de vacunación, etc.

La escuela detiene un importante papel como instancia socializadora, a medida que permite una mayor exposición a diferentes valores y comportamientos dentro del sistema educativo público. Además, proporciona un lugar de convergencia y de intercambio de sociabilidades para un alumnado socioeconómicamente más heterogéneo en comparación con los barrios Nordeste de Amaralina y Plataforma. Indagados sobre las oportunidades de la educación pública,
No. 1

Jul - Dic 2016

ISSN: 2590-9215

(En línea)

PP: 6-29 
los adolescentes entrevistados de Jaguaripe I coinciden en avaluar como positivo la cualidad de las instituciones frecuentadas y confirman la centralidad de la escuela como espacio de convivencia en la formación de redes sociales más diversificadas que transcienden su clase social.

A pesar de que no se registren señales de una integración de empleo similar al caso del Nordeste de Amaralina, la renta de los inquilinos de los conjuntos habitacionales puede ser considerada como factor limitador, el uso compartido de estructuras comunitarias como el transporte de autobús, las asociaciones (no)laicales y las áreas de diversión y recreo público (plazas, bares y restaurantes) favorece la articulación entre los integrantes de las dos áreas y contribuye a la desconstrucción de las distancias sociales entre los dos grupos de residentes.

Particularmente la abundancia de infraestructura comercial y social promueven las interacciones diarias entre los residentes de Jaguaripe I y el Conjunto Habitacional Fazenda Grande II. No obstante la relativa autonomía del local en termos de servicios y equipamientos urbanos (escuelas, supermercados, puestos de salud, hospitales, bares y restaurantes), el acceso a shopping centers y a opciones de diversión más sofisticadas demanda un desplazamiento para las áreas más centrales.

\section{Discusión de los resultados}

y Silveira (2013, pp. 397-399), resalta que la proximidad residencial del individuo pobre a los barrios de la clase media-alta no correlaciona automáticamente con una mayor articulación interclases (Almeida \& d'Andrea, 2004, pp. 105-106) o con una dinámica ascendente per se de la favela en termos de integración socioeconómica de sus habitantes.

Los patrones de movilización de las redes para la obtención de empleo y de recursos (in) materiales revelan un alto grado de homofilia y localismo y demuestran la prevalencia de lazos primarios. Corroborando con los propuestos teóricos de Wilson (1987), las externalidades negativas afectando la vida de los habitantes entrevistados del barrio periférico Plataforma impactan en la extensión y diversidad de las redes. Existe una homologia entre el bajo grado de exposición a individuos y grupos socioeconómicamente disimilares y el alto grado de localismo y homofilia caracterizando sus relaciones sociales. La centralidad de los lazos locales subraya la relevancia de las condiciones financieras en la construcción y manutención de redes mayores y más diversificadas, social e espacialmente.

Así, se verifica una interferencia negativa de social isolation en la composición de sus redes egocentradas, que puede ser interpretado tanto como resultado cuanto como elemento perpetuador de la segregación residencial económica. La clusterización a partir de redes fragmentadas, constituidas en el ambiente de la familia extensa y con escasas conexiones entre sí crea obstáculos a la movilidad económica. La promoción de estructuras de supervivencia de corto plazo a base de un patrón de sociabilidad centrado defensivamente en la familia no recompensa la instabilidad ocupacional propia al mercado informal y a la exclusión del mercado de trabajo formal.
Sin embargo, la dialéctica entre integración de empleo y evitación social, ya documentada por Ribeiro (2008, pp. 15-20) y Andrade 
En el caso de Fazenda Grande II, se observa un mayor grado de heterofilia y diversidad dentro de la composición de las redes que abstraen de las instancias primarias y denotan de una mayor dispersión espacial. Se corroboran así los resultados de McPherson et al. (2001), afirmando que los locales de trabajo y del estudio representan contextos sociales que generan menor homofilia $y$ mayor convergencia física entre personas socialmente disimilares (pp. 418-421). La vitalidad de las estructuras institucionales (escuelas, iglesias, asociaciones comunitarias, etc.) depende esencialmente de la integración en el mercado laboral formal de su población así como del soporte económico del segmento medio-popular.

En este sentido, es oportuno resaltar la importancia de la escuela pública en su función socializadora, a medida que promueve una mayor exposición de los habitantes de Jaguaripe a comportamientos y referencias sociales orientadas en la valorización de la educación y en modelos de ascensión social de la clase media-baja. Los intercambios de sociabilidad ocurriendo en las esferas vida asociativa laical y diversión abstraen de la misma clase social. Estas relaciones inter-clase facilitan el acceso a bienes y servicios en el barrio y permiten inclusive la movilización de recursos extra-comunitarios para reivindicar mejoras habitacionales en el barrio.

A pesar de no constituir una muestra estadísticamente significativa para inferir una incidencia generalizada de neighborhood effects en la organización y movilización de las redes sociales, el estudio de caso señala para significantes convergencias con los resultados de Marques (2007, p. 156162) con respecto a su observación que la participación en una gama más diversificada de esferas de sociabilidad no-primarias incide positivamente en la movilidad económica y social. Se resalta la importancia de la exploración de posiciones de intermediación, o structural holes en la terminología de Burt (1992), incorporadas por diferentes actores sociales y entidades institucionales, o bridging ties, por los cuales circulan informaciones cruciales sobre oportunidades de empleo, mientras que se confirma la importancia de los bonding ties en su función de promocionar contactos valiosos para la integración en el mercado de trabajo informal.

Al mismo tiempo, los resultados llaman la atención por el hecho que las redes inscritas en las esferas de sociabilidad familia, vecindario y amigos, con elevados niveles de localismo y de homofilia, pueden reproducir y hasta reforzar los mecanismos de pobreza en contextos de segregación, si la falta de oportunidades de interacción intergrupal e interclase se conjuga con bajos niveles de solidaridad, confianza y compromiso con obligaciones mutuas en la escala intracomunitaria. La creación de patrones de distanciamiento social y la diferenciación de ingroups y outgroups (Marsden, 1988, p. 65) a base de atributos similares, destacados tanto en las esferas familia y vecindario cuanto en el ambiente de la iglesia y otros grupos religiosos, favorece el encapsulamiento e isomorfismo (McPherson et al., 2001, p. 434) de las redes sociales y contribuye a la erosión de la eficacia colectiva de la comunidad.

Sampson et al. (1997) definen el concepto de eficacia colectiva (collective efficacy) como las expectativas compartidas y el envolvimiento de habitantes pertenecientes al mismo vecindario en actividades de soporte activo, control social y supervisión de otros individuos a partir de normas y prácticas colectivamente aceptadas y sancionadas (pp. 918-919). En otras palabras, la eficacia colectiva depende principalmente de la disposición de intervenir para un bien común de la comunidad.

Estos mecanismos operan en contextos sociales con una estructura vital de recursos socioeconómicas y se fundamentan en
No. 1

Jul - Dic 2016 ISSN: 2590-9215 (En línea) PP: 6-29 
principios de confianza, reciprocidad y solidaridad, como evidenciado en el caso de Fazenda Grande II. Mientras tanto, en los barrios de Nordeste de Amaralina y Plataforma se anuncia la erosión de la legitimidad de las normas sociales que aseguran las expectativas y obligaciones mutuas, en virtud de la fuerte ocurrencia de homicidios, asaltos y robos.

\section{Consideraciones finales}

El trabajo partió del reconocimiento de la gran relevancia del análisis de los patrones de movilización de las redes sociales en procesos de integración económica para modelos explicativos, indagando sobre las desigualdades sociales en las grandes ciudades contemporáneas, en virtud de su capacidad de reforzar o mitigar mecanismos de reproducción de la pobreza. No obstante, es oportuno enfatizar que dentro de la discusión académica sobre los presupuestos teóricos de social isolation (Wilson, 1987) persisten significantes desafíos metodológicos con respecto a las interdependencias causales entre neighborhood effects y network effects.

Frecuentemente, resulta difícil discernir analíticamente entre el impacto potencialmente perjudicial del contexto socio-residencial (la exposición a altas tasas de pobreza, desempleo y criminalidad), en la morfología de las redes sociales del individuo y el impacto potencialmente perjudicial de un específico patrón de organización de las redes sociales del individuo (alto grado de homofilia, redundancia y localismo de los lazos sociales) en la movilidad económica. Modelos de explicación sobre la reproducción de pobreza urbana, partiendo del examen de las redes sociales deben atender al nexus de causalidad recíproca entre neighborhood effects y network effects.

En este sentido, es crucial distinguir entre imposed environments y selected environments (Sharkey, 2006, pp. 826-827) para no inferir un impacto determinista del contexto social en el desempeño socioeconómico y en la composición de las redes sociales del individuo expuesto a altas tasas de pobreza y desempleo. Concomitantemente, se ruega mayor cautela analítica en la interpretación de los patrones de sociabilidad para no asociar automáticamente la homofilia, el localismo y los strong ties con o social isolation y una reducida movilidad económica del individuo.

Mientras que investigaciones cualitativas y cuantitativas de la sociología europea que han abordado los neighborhood effects, effétsquartier o Quartierseffekte (Häußermann, 2004) frecuentemente refutan la hipótesis de social isolation del individuo, en virtud del hallazgo de una mayor dispersión territorial y diversidad estructural de las redes sociales que extrapolan en muchos casos el contexto social del lugar de residencia (particularmente la escuela); en la Sociología Latinoamericana, esta teoría puede ganar mayor relevancia trayendo en consideración lo dimensionado en los patrones de sociabilidad del individuo insertado en contextos de pobreza y segregación residencial, una mayor congruencia entre el espacio geográfico y el espacio social.

Los ejemplos empíricos de Plataforma y, de una forma menos expresiva, del Nordeste de Amaralina, señalan para el efecto de encapsulamiento y fragmentación de las redes egocentradas que, además de la segregación residencial y de la segmentación social, se ve potenciado por la erosión de la confianza y de la eficacia social en el barrio. Estas dos áreas corren el riesgo de convertirse en locales socialmente invisibles, ya que se encuentran desarticulados de otros segmentos sociales de la ciudad, lo que posiblemente contribuye a la estigmatización territorial y a la deterioración socioeconómica de sus habitantes.

El caso de Fazenda Grande II demuestra que resulta imprescindible una mayor responsabilidad social del Estado por invertir en infraestructura y equipamientos urbanos 
con alcance socialmente integrativo, para promover una mayor convergencia física de individuos y grupos sociales pertenecientes a diferentes clases sociales.

\section{Referencias Bibliográficas}

Almeida, R. d, D'Andrea, T. (2004). Pobreza e redes sociais em uma favela paulistana. Novos Estudos, 68, 94-106.

Andrade, L. T., Silveira, L. S. (2013). Efeitoterritório. Explorações em torno de um conceito sociológico. Civitas, 13 (2), 381-402.

Bourdieu, P. (1986). The forms of capital. En J. G. Richardson (ed.), Handbook of theory and research for the sociology of education (pp. 241-258). New York: Greenwood Press.

Bourdieu, P. (1999). Efeitos do lugar. En A Miséria do Mundo (159-204). Petrópolis: Vozes.

Briggs, X de S. (1998). Brown Kids in White Suburbs: Housing Mobility and the Multiple Faces of Social Capital. Housing Policy Debate, 9 (1), 177221.

Briggs, X. de S. (2003). Bridging Networks, Social Capital, and Racial Segregation in America. John F. Kennedy School of Government Faculty Research Working Paper Series Paper RWP02011.

Burt, R. S. (1992). Structural holes: The social structure of competition. Cambridge (MA): Cambridge University Press.

Carvalho, I. M. M. de; Pereira, G. C. (eds.) (2014). Salvador: transformações na ordem urbana: metrópoles: território, coesão social e governança democrática. Rio de Janeiro: Letra Capital.
Castells, M. (1983). A questão urbana. Rio de Janeiro: Paz e Terra.

Coleman, J. S. (1988). Social capital and the creation of human capital. American Journal of Sociology, 94, 95-120.

Gans, H. (1962). The Urban Villagers. New York: Free Press

Granovetter, M. (1982). The Strengh of Weak Ties: A Network Theory Revisited. En P. V. Marsden, N. Lin (eds.) Social Structure and Network Analysis (pp. 105-130). Beverly Hills (CA): Sage.

Hannerz, U. (1969). Soulside: Inquiries into Ghetto Culture and Community. New York: Columbia University Press.

Häußermann, H. (ed.) (2004). An den Rändern der Städte. Armut und Ausgrenzung. Frankfurt am Main: Suhrkamp.

Jencks, C., y Mayer, S. E. (1990). The Social Consequences of Growing up in a Poor Neighborhood. En L. Lynn, M. McGreary (eds.), Inner-City Poverty in the United States (pp. 111186). Washington, D.C.: National Academies Press.

Kaztman, R. (1999). Segregación Residencial y Desigualdades Sociales en Montevideu. Revista de la CEPAL, 1 , $1-63$.

Kaztman, R. (2001). Seducidos y 27 abandonados: el aislamiento social de los pobres urbanos. Revista de la Cepal, 75, 171-189.

Kaztman, R., y Filgueira, F. (2006). Las normas como bien público y como bien privado: reflexiones en las fronteras del enfoque AVEO. Montevideo: Universidad Católica del Uruguay.
Vol. 1

No. 1

Jul - Dic 2016

ISSN: $2590-9215$

(En línea) PP: 6-29 
Kaztman, R., Retamoso, A. (2005). Introducción: empleo, concentración espacial y endurecimiento, de la pobreza urbana. Revista de la CEPAL, $85,132-148$

Marques, E. (2007). Redes sociais, segregação e pobreza em São Paulo. (Tese de Livre Docência). São Paulo: Editora Unesp.

Marsden, P. V. (1988). Homogeneity in confiding relations. Social Networks, 10, 57-76.

Massey, D., y Denton, N. (1993). American Apartheid: Segregation and the Making of the Underclass. New York: Harvard University Press.

McPherson, M., Smith-Lovin, L., Cook, J. M. (2001). Birds of a feather: Homophily in social networks. Annual Review of Sociology, 27, 415-444.

Murray, C. (2015). Losing ground. New York: Basic Books.

Park, R. E. (1987[1915]). A Cidade: sugestões para a investigação do comportamento humano no meio urbano. En O. G. Velho (ed.), O fenômeno urbano (pp. 26-67). Rio de Janeiro: Guanabara.

Park, R. E., Burgess, E. W., McKenzie, R. D. (1925). The City. Chicago: University of Chicago Press.
Ribeiro, L. C. de Q., y Kaztman, R. (eds.). (2008). A cidade contra a escola? Segregação urbana e desigualdades educacionais em grandes cidades da América Latina. Rio de Janeiro: Letra Capital.

Ribeiro, L. C. de Q., Kolinski, M. C. (2009). Efeito metrópole e acesso às oportunidades educacionais. Revista Eure, 35 (106), 101-129.

Ribeiro, L. C. de Q., Lago, L. C. do. (2001). A Oposição Favela-Bairro no Espaço Social do Rio de Janeiro. São Paulo em Perspectiva, 15 (1), 144-154.

Sabatini, F. (2003). The Social Spatial Segregation in the Cities of Latin America. Social Development Strategy Document. Washington D.C.: InterAmerican Development Bank.

Sabatini, F., Cáceres, G., Cerda, J. (Julio, 2001). Residential Segregation Pattern Changes in Main Chilean Cities: Scale Shifts and Increasing Malignancy. En International Seminar on Segregation in the City. Cambridge (MA): Lincoln Institute of Land Policy.

Sampson, R. J., Raudenbusch, S. W., Earls, F. (1997). Neighborhood and Violent Crime: A Multilevel Study of Collective Efficacy. Science, 277 (15), 918-924.

Sampson, R. J. (2004). Neighborhood and Community: Collective Efficacy and Community Safety. New Economy, $11,106-113$.

Ribeiro, L. C. de Q. (2008). Proximidade territorial e distância social: reflexões sobre o efeito de lugar a partir de um enclave urbano. VeraCidade, 3 (3), $1-21$. collapse of America's social capital. New York: Simon and Shuster. 
Sharkey, P., Sampson, R. J. (2010). Destination Effects: Residential Mobility and Trajectories of Adolescent Violence in a Stratified Metropolis. Criminology, 48 (3), 639-681.

Shaw, C., y McKay, H. (1942). Juvenile Delinquency and Urban Areas. Chicago: University of Chicago Press.

Simmel, G. (1983[1902]. Metrópole e Vida Mental. En G. Velho (ed.), $O$ fenômeno urbano (pp. 11-25). Rio de Janeiro: Guanabara.

Small, M. L. (2004). Villa Victoria: The Transformation of Social Capital in a Boston Barrio. Chicago: University of Chicago Press.

Small, M. L., Newman, K. (2001). Urban poverty after 'The truly disadvantaged': the rediscovery of the family, the neighborhood, and culture. Annual Review of Sociology, 27, 2345.

Tigges, L. M., Browne, I., Green, G. P. (1998). Social Isolation of the Urban Poor: Race, Class, and Neighborhood Effects on Social Resources. The Sociological Quarterly, 39 (1), 53-77.

Torres, H. da G., y Bichir, R. M., y Gomes, S., y Pavez, T. R. C. (2008). Educação na Periferia de São Paulo: ou como pensar as desigualdades educacionais? En L. C. de Q. Ribeiro, R. Kaztman (eds.), A cidade contra a escola: segregação urbana e desigualdades educacionais (pp. 59-90). Rio de Janeiro: Letra Capital.

Venkatesh, S. (2000). American Project: The Rise and Fall of a Modern Ghetto. Cambridge (MA): Harvard University Press.
Wellman, B. (1979). The community question: the intimate networks of East Yorkers. American Journal of Sociology, 84 (5), 1201-1231.

Wellman, B., Wortley, S. (1990). Different strokes from different folks: Community ties and social support. American Journal of Sociology, 96 (3), 558-588.

Wilson, W. J. (1987). The truly disadvantaged:

\section{the inner city, the underclass and
public policy. Chicago: University \\ the inner city, the underclass and
public policy. Chicago: University Press.}

Cúcuta-Colombia

Vol. 1

No. 1

Jul - Dic 2016

ISSN: 2590-9215

(En línea)

PP: 6-29 